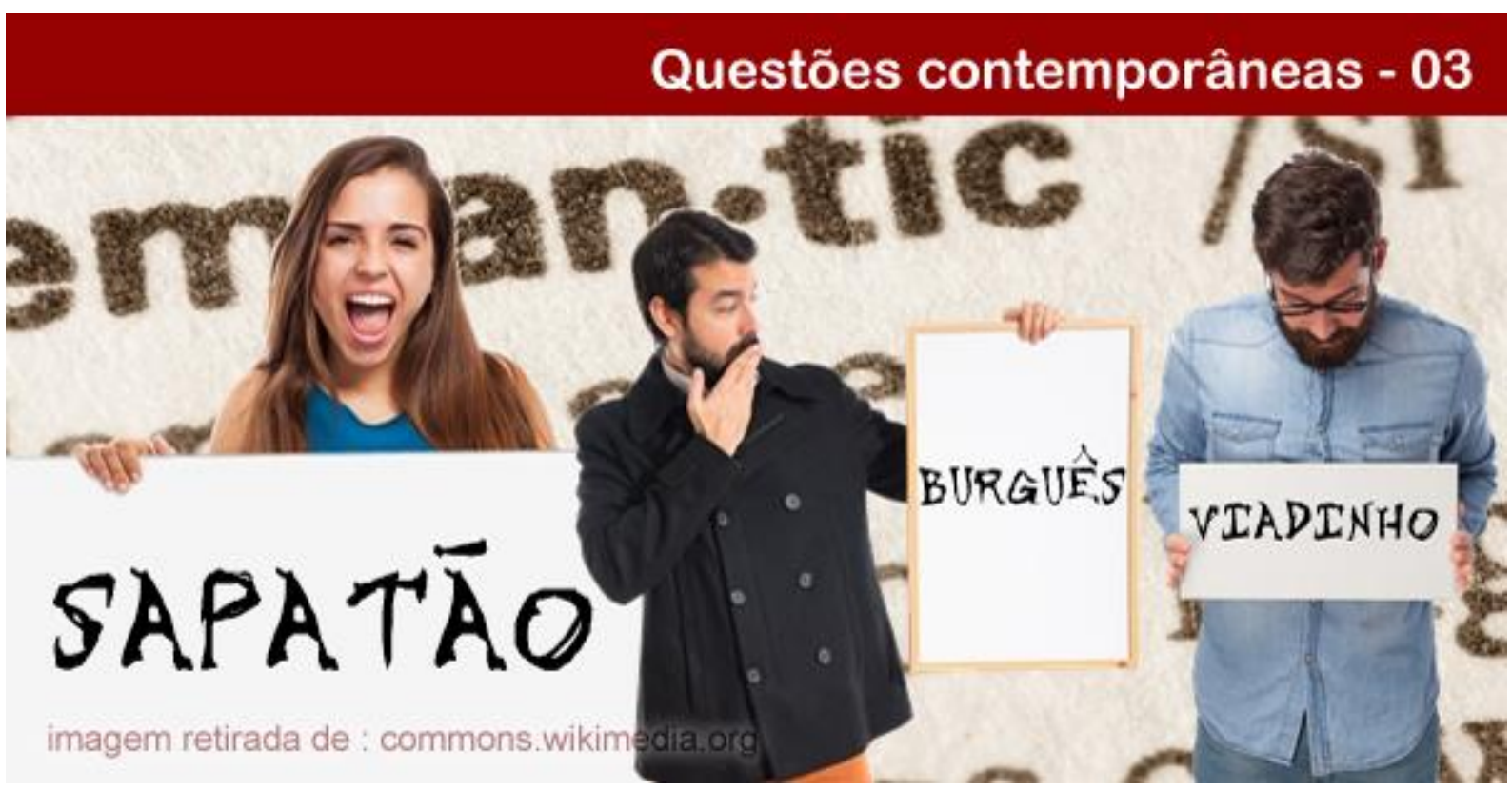

\title{
SEMÂNTICA PARA PEJORATIVOS: CONTRA-ARGUMENTOS À INOCÊNCIA SEMÂNTICA
}

\section{John Lennon Lindemann}

Professor. Mestre e Licenciado em Filosofia pela Universidade Federal de Santa Maria. Membro da Association for Symbolic Logic (Cambridge). E-mail: johnllindemann@hotmail.com.

Resumo: Os pejorativos tem sido objeto de uma crescente literatura em filosofia. Hom e May (2013) defendem a tese da Inocência Semântica para explicar a força depreciativa dos pejorativos, tese que recebeu ataques de Sennet e Copp (2014). O objetivo deste artigo é apresentar contribuições a esta discussão, defendendo a tese da Inocência Semântica dos ataques recebidos de Sennet e Copp (2014), mas apresentando um novo argumento contra suas pretensões, mostrando que a tese da Inocência Semântica falha em reconhecer o caráter depreciativo de injurias cuja contraparte neutra seja falsa.

Palavras-chave: Semântica. Pejorativos. Injúrias.

\section{SEMANTIC FOR PEJORATIVES: ARGUMENTS AGAINST THE SEMANTIC INNOCENCE}

Abstract: The pejorative have been the object of a growing literature in philosophy. Hom and May (2013) defend the Semantic Innocence thesis to explain a depreciative force of the pejoratives, receiving attacks from Sennet and Copp (2014). The purpose of this article is to present contributions to this discussion, defending the Semantic Innocence thesis of the attacks received from Sennet and Copp (2014), but presenting a new argument against its pretensions, showing that the Semantic Innocence thesis fails to recognize the derogatory character of insults whose neutral counterpart is false.

Keywords: Semantics. Pejorative. Injuries.

\section{Introdução}

Por que alguns pejorativos ofendem mais do que os outros? Por qual razão ser chamado de "bobo" não nos ofende tanto quanto ser chamado de "filho da puta"? Enfim, como entendemos a força depreciativa dos pejorativos?

\section{POLÊM!CA | LABORÊ (t)}

Polêmica - Revista Eletrônica da Uerj - Rua São Francisco Xavier, 524, $1^{\circ}$ andar bloco D, sl.1001 • Tels.: +55 21 2334-4088/4087 • http://www.e-publicacoes.uerj.br/index.php/polemica/index http://www.labore.uerj.br • laboreuerj@yahoo.com.br 
Entender a força depreciativa dos pejorativos é apenas uma das muitas questões teóricas que eles suscitam, pois os "pejorativos demonstram uma grande variedade de fenômenos complexos"1 (HOM, 2010, p. 164, tradução nossa), como o fenômeno da apropriação, um fenômeno social caracterizado pela apropriação do uso de termos pejorativos por parte dos grupos sociais originalmente atacados, ou como o fenômeno da variabilidade sintática, um fenômeno linguístico caracterizado pela ocorrência do mesmo termo pejorativo em distintas posições sintáticas (HOM, 2010). Dada sua complexidade, os pejorativos se tornaram objeto de estudo em vários campos do conhecimento, incluindo estudos filosóficos recentes acerca de como devemos compreender sua força depreciativa (CROOM, 2013).

As estratégias teóricas para o tratamento da problemática envolvendo a força depreciativa dos pejorativos podem ser divididas em dois grandes grupos, a saber, o das estratégias semânticas e não semânticas (SENNET; COPP, 2014).

Cabe especificar que as teorias semânticas limitam-se à semântica formal, suposta neste trabalho, tal como encontrada nos trabalhos de Hom (2008), Richard (2008) e Bach (2014), que visam explicar o caráter depreciativo dos pejorativos por meio de uma análise verofuncional da linguagem, recorrendo às condições de verdade ou falsidade das frases em que os pejorativos ocorrem para explicar o seu significado e caráter depreciativo.

Os filósofos que adotam teorias não-semânticas, como Hedger (2012), Potts (2007) e Jeshion (2013), visam, em sua maioria, explicar o caráter depreciativo dos pejorativos por meio de características pragmáticas da linguagem. Visando limitar o objeto da presente investigação, não trataremos de teorias não-semânticas, reservadas como objeto de futuras investigações.

Segundo Hom (2010), os exemplos paradigmáticos de pejorativos são: palavrões (por exemplo: "porra" e "merda"), ofensas (por exemplo: "idiota" e "estúpido") e injúrias (por exemplo: "sapatona" e "macaco"). As injúrias se distinguem das ofensas por serem direcionadas a grupos sociais específicos, podendo ser divididas de acordo com os grupos sociais que visam atacar, como, por exemplo, injúrias raciais e injúrias sexuais.

Sobre injúrias em geral, Hom e May (2013) defendem a tese da Inocência Semântica, isto é, uma abordagem semântica formal que pressupõe um realismo moral. Compreende-se realismo moral como a posição segundo a qual as reivindicações morais são fatos passíveis de

\footnotetext{
${ }^{1}$ Do original: "Pejoratives demonstrate a wide array of complex phenomena".

\section{POLÊM!CA $\mid$ LABORE}


valor de verdade (SAYRE; MCCORD, 2015). Assim, uma sentença como, por exemplo, “A honestidade é boa" expressa um fato passível de valor de verdade e é análoga a sentença “Todos os corvos são pretos". Segundo a tese da Inocência Semântica, dado o seu pressuposto de realismo moral, todo termo pejorativo é um termo de extensionalidade nula, isto é, um termo sem instâncias em nosso mundo.

Por outro lado, Sennet e Copp (2014) formularam uma série de argumentos contra a tese da Inocência Semântica, entre os quais se destaca o argumento que assume a forma de reductio ad absurdum, supondo a tese da Inocência Semântica para derivar uma consequência absurda, e o argumento que recorre à tese da verdade por vacuidade, segundo a qual toda sentença que predique algo a um termo com extensão nula é verdadeira. Argumentamos que a tese da Inocência Semântica, embora resista aos ataques de Sennet e Copp (2014), falha em determinar o caráter depreciativo de injúrias em alguns casos específicos de seu uso.

Com o objetivo de contribuir com esse polêmico debate, o presente trabalho se divide em cinco seções. Apresentamos uma reconstrução da tese da Inocência Semântica na primeira seção e argumentamos contra os ataques que ela sofreu de Sennet e Copp (2014), nas duas seções seguintes. Em contrapartida, a quinta seção apresenta um exemplo de caso cuja análise, realizada na sexta seção, constituí um novo argumento contra a tese da Inocência Semântica, demonstrando que sua estratégia, embora resista aos ataques de Sennet e Copp (2014), não funciona para todos os casos.

\section{Tese da inocência semântica}

Hom e May (2013) definem Inocência Semântica como o realismo moral aplicado aos pejorativos, por meio do qual se assume a existência de uma estrutura moral na qual os termos pejorativos têm sempre uma extensionalidade nula. Isso significa que existem instâncias para "homossexuais femininas" e que não existe, no mundo em que vivemos, instâncias para "sapatonas". Esta tese pode ser expressa da seguinte forma:

(1) Nenhuma homossexual feminina é sapatona.

(2) Não existem sapatonas.

(3) Existem homossexuais femininas.

\section{POLÊM!CA $\mid$ LABORE}


Segundo os autores da tese da Inocência Semântica, as sentenças (1), (2) e (3) são verdadeiras simultaneamente.

Mas por que (2) é verdadeira? Basicamente, em função da tese da extensionalidade nula, defendida pelos autores da seguinte forma:

Se os significados linguísticos dos pejorativos implicam que eles têm extensões nãonulas, isso implica que existem kikes, niggers e chinks ${ }^{2} \mathrm{e}$, consequentemente, que as crenças dos racistas são verdadeiras e justificadas.

Em nossa opinião, qualquer teoria com essa implicação é inaceitável, e dificilmente pensamos que alguém deve discordar. ${ }^{3}$ (HOM; MAY, 2013, p. 297-298, tradução nossa).

Assim, a tese da extensionalidade nula consiste em afirmar que todos os pejorativos possuem extensão nula. Se aceitarmos que as injúrias não têm extensionalidade nula, segue-se que existem instâncias para injúrias no mundo em que vivemos. Consequentemente, alguém que defenda uma crença racista ou sexista está justificado, uma vez que os correlatos de seus termos pejorativos possuem instâncias. Hom e May (2013) não admitem tal consequência, dado que, para eles, todos os pejorativos tem extensão nula.

Apesar da extensionalidade nula das injúrias, não podemos negar que o alvo de uma injúria sexual como "sapatão" são as homossexuais femininas. Segue-se que o pejorativo "sapatão" possuí uma contraparte neutra, a saber, "homossexual feminina". Se as injúrias têm uma relação com suas contrapartes neutras, que relação é essa? Como explicar que a expressão "homossexual feminina", a qual possui instâncias, mantenha uma relação qualquer com a injúria "sapatão", de extensionalidade nula?

Os autores respondem que há uma relação entre pejorativos e suas contrapartes neutras (HOM; MAY, 2013), e explicam esta relação por meio da função $\operatorname{PEJ}(\xi)$, tal como se segue:

\begin{abstract}
O sentido expresso pela PEJ denota uma função de segundo nível que se combina com um conceito de primeiro nível (por exemplo, raça, gênero, religião ou classe) para formar um conceito pejorativo complexo de primeiro nível. O conceito pejorativo complexo toma os objetos como entradas e tem a falsidade como sua saída. $^{4}$ (HOM, MAY, 2013, p. 298, tradução nossa).
\end{abstract}

\footnotetext{
2 "Kikes, niggers e chinks" são injurias raciais para, respectivamente, judeus, negros e chineses.

${ }^{3}$ Do original: "If the linguistic meanings of pejoratives entail that they have non-null extensions, then this implies that there are kikes, niggers, and chinks, and accordingly that racists' beliefs are true and justified.

To our mind, any theory with this implication is unacceptable, and we hardly think anyone would disagree.

${ }^{4}$ Do original: The sense expressed by PEJ denotes a second-level function that combines with a first-level concept, (e.g. of race, gender, religion, or class) to form a complex first-level pejorative concept. The complex pejorative concept takes objects as inputs, and has falsity as its output.
}

\title{
POLÊM!CA $\mid$ LABORE
}

Polêmica - Revista Eletrônica da Uerj - Rua São Francisco Xavier, 524, $1^{\circ}$ andar

bloco D, sl.1001 • Tels.: +55 21 2334-4088/4087 • http://www.e-publicacoes.uerj.br/index.php/polemica/index

http://www.labore.uerj.br • laboreuerj@yahoo.com.br 
Assim, dado um domínio constituído apenas e tão somente por contrapartes neutras, a função PEJ é a soma da contraparte neutra com atributos falsos e depreciativos, cujo resultado é um termo complexo e pejorativo. Por exemplo:

$$
\operatorname{PEJ}(\text { Homossexual feminina })=\text { Sapatão }
$$

No exemplo acima, a função PEJ seleciona a contraparte neutra "homossexual feminina" e gera a injúria sexual "sapatão". Desse modo, pejorativos são tratados como termos complexos, ou seja, expressões constituídas pela contraparte neutra combinada com atributos falsos e depreciativos por meio da aplicação da função PEJ (HOM; MAY, 2013).

Ainda no exemplo de aplicação da função PEJ acima, podemos perceber que a contraparte neutra possui instâncias. No entanto, na medida em que a ela se acrescentam atributos depreciativos por meio da função PEJ, acrescentam-se ao modo de apresentação de "homossexual feminina" certas características falsas e depreciativas, deixando, assim, de possuir qualquer referência.

Percebe-se que há, na teoria da Inocência Semântica, um forte comprometimento com a existência de uma estrutura moral do mundo, onde a nulidade da extensão de termos pejorativos pode ser sempre constatada a priori. Essa é uma das abordagens usuais no campo da Filosofia, embora muitos filósofos, como Nietzsche (1999), discutem a moral sobre outros termos.

\section{Primeiro contra-argumento e uma possível resposta}

Sennet e Copp (2014) argumentam contra estratégias teóricas que recorrem à semântica formal para o tratamento de pejorativos, atacando especialmente a tese de Hom e May (2013). Um dos contra-argumentos à Inocência Semântica elaborados por Sennet e Copp (2014) assume a forma de reductio ad absurdum. Compreende-se como reductio ad absurdum todo argumento que supõe a tese que deseja atacar e dela deriva uma consequência absurda, concluindo que a suposição original deve estar errada. Neste contra-argumento, Sennet e Copp (2014) recorrem a um possível uso da própria função PEJ para provar que dela se derivam consequências absurdas, tal como se segue, dado o seguinte uso da função PEJ:

\section{POLÊM!CA $\mid$ LABORE}




\section{(5) PEJ(Burguês)=Explorador}

No exemplo de uso acima, a função PEJ é aplicada ao termo "burguês", que deve ser considerado como contraparte neutra, ao passo que "explorador" deve ser considerado como o

pejorativo resultante. É fácil encontrar pessoas com a crença de que todos os indivíduos que pertencem à classe burguesa devem ser depreciados. Pensemos no caso de um militante marxista que sustenta crenças antiburguesas. Nosso militante hipotético deprecia os burgueses, chamando-os de exploradores.

Esse é um uso legítimo da função PEJ, pois a relação entre a contraparte neutra e o termo "explorador" enquanto pejorativo parece ser adequadamente explicada pela característica lexical da função. Isso se torna, no entanto, um problema para a tese da Inocência Semântica, na medida em que, segundo ela, o termo "explorador" seria um pejorativo e, enquanto tal, sua extensão deve ser nula.

Mesmo que o termo "explorador" possa ser usado de modo legítimo como injúria aplicada a um grupo social específico, parece um absurdo inferir que sua extensão seja nula, pois existem instâncias para indivíduos que abusam dos serviços de outra pessoa em benefício próprio e, assim sendo, existem instâncias para o termo "explorador".

Acreditamos que Hom e May (2013) poderiam se defender deste ataque tomando o termo complexo resultante da função PEJ aplicada a "burguês" como um termo que, de fato, possui extensão nula, observando que a palavra "explorador" pode ter vários significados diferentes. Em um sentido, "explorador" predica aquele que abusa dos serviços de alguém em benefício próprio. Neste sentido, ele não possui extensão nula, pois não é usado como pejorativo a um grupo social determinado. Em outro sentido, explorador é um pejorativo obtido por meio da função PEJ aplicada ao termo burguês, usado por pessoas com crenças antiburguesas e sua extensão é nula. Sob tal possível interpretação, os dois termos possuem em comum apenas o sinal, sendo palavras homônimas. Lembremo-nos que o termo "explorador", em sentido alternativo, também pode significar a atividade de pessoas que se aventuram em lugares inusitados, como cavernas.

Segue-se que a aplicação da função PEJ de Sennet e Copp (2014) é correta, gerando o sinal "explorador", tomado como pejorativo para burguês, que tem extensão nula e seu sentido é "sujeito imoral devido à classe burguesa a qual pertence". Entretanto, há um termo

\section{POLÊM!CA $\mid$ LABORE}


homônimo, onde o sinal "explorador", enquanto conceito não pejorativo, tem o sentido de "sujeito que abusa dos serviços de alguém em benefício próprio", de tal modo que sua extensão não é nula, possuindo inclusive alguns burgueses como instâncias.

Assim, a tese da Inocência Semântica resiste ao ataque de Sennet e Copp (2014), explicitando não apenas que todo termo gerado pela função PEJ é um pejorativo com extensão nula, mas também explicitando que há casos em que o termo gerado pode ser expresso por um sinal que também é comumente usado para expressar um termo não pejorativo. Nestes casos, deve-se compreender o termo complexo gerado pela função PEJ apenas como homônimo de seu correlato não pejorativo. Em síntese: se foi gerado pela função PEJ, então o termo é necessariamente um pejorativo nulo em extensão, possuindo um significado distinto de qualquer termo que possua extensão, mesmo quando expressos pelo mesmo sinal.

\section{Segundo contra-argumento e uma possível resposta}

Outro ataque de Sennet e Copp (2014) à tese da Inocência Semântica refere-se às suas consequências indesejáveis em proposições vacuamente verdadeiras.

Admitir a verdade por vacuidade é lugar comum na lógica contemporânea, onde proposições do tipo “Todo F é G” são verdadeiras quando a extensão de F é nula.

A proposição “Todo F é G” pode ser formalizada da seguinte forma:

$$
(\forall x)(F x \rightarrow G x)
$$

A formalização acima é sempre verdadeira quando a extensão de $\mathrm{F}$ é nula, o "que significa o mesmo que 'não existem $F$ que não são $G$ ', o que é obviamente verdadeiro"5 (BLACKBURN, 1994, p. 388, tradução nossa).

Se considerarmos a intenção dos autores da tese da Inocência Semântica, parece que eles reivindicariam a falsidade da frase "Todo bicha é merecedor de uma morte cruel”. Mas, uma frase como “Todo F é G" é verdadeira se a extensão de F for nula, sendo exatamente esse o caso da frase contendo o termo pejorativo supracitada, dada a extensionalidade nula do pejorativo "bicha". Logo, a frase "Todo bicha é merecedor de uma morte cruel" é verdadeira.

${ }^{5}$ Do original: "It means the same as 'there are no F things that are not G', which is obviously true".

\section{POLÊM!CA $\mid$ LABORE}


A tese da verdade por vacuidade é lugar comum entre os lógicos contemporâneos. No entanto, ao aplicarmos suas consequências à tese da Inocência Semântica, segue-se que uma frase como "Todo bicha é merecedor de uma morte cruel" será verdadeira, o que parece contrário às intenções dos criadores da tese da Inocência Semântica. Afirmar a verdade de uma frase como "Todo bicha é merecedor de uma morte cruel" pode ter consequência indesejáveis, propagando a discriminação e o ódio, incluindo crimes de ódio.

Defender a tese da Inocência Semântica contra esse ataque consiste no esclarecimento da tese da extensionalidade nula dos pejorativos, ressaltando que a frase "Todo bicha é merecedor de uma morte cruel" é verdadeira justamente devido à não existência de instâncias para o termo "bicha". Assim, implica afirmar que as frases "Não existem bichas que não são merecedores de uma morte cruel" e "Não existem bichas que são merecedores de uma morte cruel" são verdadeiras simultaneamente.

Os defensores da tese da Inocência Semântica não precisam reivindicar a falsidade da frase "Todo bicha é merecedor de uma morte cruel", dado que a extensionalidade nula dos pejorativos lhes assegura que não há instâncias para "bicha" que possam sofrer qualquer tipo de morte.

A respeito das possíveis consequências indesejáveis da defesa de uma teoria que afirma a verdade de frases como "Todo bicha é merecedor de uma morte cruel", acreditamos que Hom e May (2013) poderiam se defender desse ataque argumentando que as pessoas que compreendem a tese da Inocência Semântica a tal ponto de reconhecerem a verdade dessas frases também compreendem que elas não possuem consequências indesejáveis.

\section{Um exemplo de caso}

Esta seção dedica-se à apresentação de um exemplo de caso comum ao uso de injúrias, explicitando o contexto de uso para análise verofuncional. A análise desse caso mostrará consequências problemáticas à tese da Inocência Semântica.

Imagine que o Sujeito $\mathrm{X}$ é tímido e se mudou recentemente para uma pequena casa, cercado por vizinhas.

Sujeito X é heterossexual, mas sua timidez o impede de ter uma namorada, de modo que apenas seus amigos o visitam. Em não raras ocasiões, alguns amigos até passam a noite em sua companhia para beberem e jogarem videogame.

\section{POLÊM!CA $\mid$ LABORE}


O tempo passa e as vizinhas percebem que Sujeito $\mathrm{X}$ não recebe visitas femininas. Certo dia, uma delas, enquanto varria o pátio da própria casa - estratégia usada para cuidar da vida alheia - vê um dos amigos do Sujeito $\mathrm{X}$ indo embora após ter passado a noite em sua companhia. Eis que a vizinha infere erroneamente: "o vizinho novo é homossexual”. O boato se espalha.

Em breve o boato chega aos ouvidos de uma vizinha preconceituosa que começa a repassar a seguinte frase: "O vizinho novo é viadinho". O Sujeito X percebe que as vizinhas começam a tratá-lo de modo diferente e algumas até com desprezo.

Logo o boato chega aos ouvidos do próprio Sujeito X. Felizmente, ele é bem resolvido e não se preocupa com as opiniões de suas vizinhas acerca de sua sexualidade.

\section{Análise do exemplo de caso}

Podemos analisar o pejorativo "viadinho" da seguinte maneira, por meio do recurso da função PEJ:

\section{PEJ $($ Homossexual $)=$ Viadinho}

Agora, voltemos nossa atenção aos boatos espalhados pelas vizinhas, que podem ser formalizados como se seguem, onde "P" representa "vizinho novo", "R" representa "homossexual" e "Q" representa "viadinho".

(9) $\quad \mathrm{PEJ}(\mathrm{R})=\mathrm{Q}$

$$
\exists \mathrm{x}(\mathrm{Px} \rightarrow \mathrm{Qx})
$$

Lê-se em (8): Existe ao menos um x tal que, se x é P, então x é R. Em (9), temos a aplicação da função PEJ em R, resultando no termo Q, que representa o pejorativo. Lê-se em (10): Existe ao menos um x tal que, se este x é P, então este x é Q.

Verifiquemos a referência de (8) e (10), lembrando que, para Frege (1962), a referência de uma sentença assertiva é sempre o seu valor de verdade.

\section{POLÊM!CA $\mid$ LABORE}


Em (8) não há a ocorrência de termos gerados pela função PEJ, sendo uma sentença sem nenhum valor depreciativo. Mas a sua referência é o Falso, sendo falsa a posteriori, pois pode-se constatar empiricamente que o vizinho novo não é homossexual. Em (10), a referência também é o Falso, dada a vacuidade de $\mathrm{Q}$ em decorrência da tese da extensionalidade nula, sendo falsa a priori, supondo o realismo moral da tese da Inocência Semântica.

Se o Sujeito $X$ de fato fosse homossexual, então, supondo a tese da Inocência Semântica, (8) seria verdadeira e (10) continuaria sendo falsa. Mas, dado o exemplo, (8) e (10) são sentenças que possuem a mesma referência, a saber, o Falso. Não há nenhuma característica de distinção na análise verofuncional das duas sentenças que nos permita distinguir porque uma é depreciativa e a outra não.

A tese da Inocência Semântica se propõe a explicitar o caráter depreciativo das injúrias através de uma análise verofuncional. A estratégia se mostra eficaz nos casos em que a sentença que contém uma contraparte neutra é verdadeira, explicitando o caráter depreciativo do pejorativo por meio da mudança do valor de verdade atribuído à sentença em que ele ocorre - que se torna falsa graças ao acréscimo de características depreciativas à contraparte neutra via função PEJ.

Como vimos, a análise do exemplo identifica um caso em que a sentença que contém uma contraparte neutra já é falsa e continua sendo falsa, mesmo após ter um termo neutro substituído por um pejorativo. Segue-se que, por meio de uma análise verofuncional, não encontramos nenhuma caraterística pela qual possamos explicitar a força depreciativa da sentença contendo um pejorativo, o que é um problema para uma tese que se propõe a explicitar o caráter depreciativo dos pejorativos via análise verofuncional.

Em síntese, se a função PEJ seleciona uma contraparte neutra que é falsa a posteriori e gera um pejorativo que é falso a priori, segue-se que a proposição com a contraparte neutra e a proposição com o respectivo pejorativo possuem o mesmo valor de verdade, mostrando que uma análise verofuncional, tal como proposta pela tese da Inocência Semântica, sequer nos permitiria identificar em qual das frases ocorre um pejorativo.

\section{POLÊM!CA $\mid$ LABORE}




\section{Considerações finais}

O objetivo deste artigo foi, após uma breve apresentação da tese da Inocência Semântica, defendermos tal tese de dois contra-argumentos de Sennet e Copp (2014) para, em seguida, apresentarmos um novo argumento contra as pretensões dos defensores da Inocência Semântica.

Os filósofos Hom e May (2013) defendem a tese da Inocência Semântica, uma estratégia semântica formal que explica a força depreciativa dos pejorativos recorrendo a uma análises verofuncional da linguagem, onde toda injúria é considerada como termo complexo de extensão nula que surge pela aplicação da função PEJ a sua respectiva contraparte neutra.

O primeiro ataque de Sennet e Copp (2014) utiliza a própria função PEJ para gerar um termo que, segundo os autores, possuí instâncias. Defendemos a tese da Inocência Semântica desse ataque, explicitando que o termo resultante da função PEJ deve sim ser considerado como pejorativo de extensão nula, porém, há uma palavra homônima a tal termo que não é um pejorativo. Com base nesse fato, argumentamos que o ataque não se sustenta, pois, surge apenas em virtude de uma confusão entre termos homônimos.

O segundo ataque de Sennet e Copp (2014) analisado neste artigo se baseia na tese da verdade por vacuidade, gerando frases cuja asserção de verdade parece contrária às intenções de Hom e May (2013). Defendemos a tese da Inocência Semântica contra esse ataque, argumentando que identificar a verdade dessas frases exige uma compreensão da tese a tal ponto que a intenção dos autores estará suficientemente clara.

Por fim, apresentamos um contra-argumento original para frustrar o projeto de Hom e May (2013), recorrendo a um exemplo de caso onde a contraparte neutra já era falsa $a$ posteriori e, após a aplicação da função PEJ, continua sendo falsa, agora a priori, de modo que uma análise verofuncional sequer permite identificar qual dos dois termos é pejorativo.

Embora apresentemos um ataque contra a abordagem semântica formal de Hom e May (2013), não se segue que tal ataque atinja outras possíveis abordagens semânticas, limitandose a uma barreira específica apenas para estratégias teóricas de semântica formal como a de Hom e May (2013), que visam explicar o caráter depreciativo dos pejorativos por meio de uma análise verofuncional da linguagem. Estaríamos caindo na falácia da generalização apressada se descartássemos todas as possibilidades de teorias semânticas apenas por identificarmos um problema em uma abordagem específica.

\section{POLÊM!CA $\mid$ LABORE}


Sem concluir mais do que é possível, encerramos este artigo almejando ter alcançado sua modesta meta: apresentar uma pequena contribuição à polêmica controvérsia filosófica sobre a força depreciativa dos pejorativos.

\section{Referências}

BACH, K. Loaded words: On the semantics and pragmatics of slurs. In: PACIFIC APA MEETING. Presented to the 2014 meetings of the Pacific Division of the American Philosophical Association. San Diego: [s.n.], 2014. Disponível em: <http://online.sfsu.edu/kbach/Bach.LoadedWords.APA.pdf>. Acesso em: 11 dez. 2016.

BLACKBURN, S. Vacuous. In: (Org.). The Oxford Dictionary of Philosophy. Oxford: Oxford University Press, 1994. p. 388.

CROOM, A. M. The Semantic of slurs: A refutation of pure expressivism. Language Sciences, Amsterdã, n. 41, Jan. 2013. p. 227-242. Disponível em:

<https://semanticsarchive.net/Archive/GRlOGI5O/The\%20semantics\%20of\%20slurs\%20A\%20refutation\%20of $\% 20$ pure\%20expressivism.pdf $>$. Acesso em: 1 jul. 2018.

FREGE, G. Über Sinn und Bedeutung. In: PATZIG, G. (Org.). Funktion, Begriff, Bedeutung: Fünf logische Studien. Göttingen: Vandenhoek \& Ruprecht, 1962. p. 40-65.

HEDGER, J. The Semantics of Racial Slurs: Using Kaplan's Framework to Provide a Theory of the Meaning of Derogatory Epithets. Linguistic and Philosophical Investigations, New York, n. 11, 2012. p.74-84.

HOM, C. Pejoratives. Philosophy Compass, Nova Jersey, v. 5, n. 2, 2010. p. 164-185. Disponível em: <http://onlinelibrary.wiley.com/doi/10.1111/j.1747-9991.2009.00274.x/epdf> Acesso em: 11 nov. 2016.

The Semantics of Racial Epithets. The Journal of Philosophy, New York, v. 105, n. 8, 2008. Disponível em: <http://www.jstor.org/stable/20620116>Acesso em: 12 nov. 15.

HOM, C.; MAY, R. Moral and Semantic Innocence. Analytic Philosophy, Nova Jersey, v. 54, n. 3, 2013. p. 293-313. Disponível em: <http://onlinelibrary.wiley.com/doi/10.1111/phib.12020/pdf〉. Acesso em: 12 nov. 15.

JESHION, R. Expressivism and the Offensiveness of Slurs. Philosophical Perspectives, Nova Jersey, v. 27, 2013. Disponível em: <http://onlinelibrary.wiley.com/doi/10.1111/phpe.12027/abstract>. Acesso em: 12 nov. 2014.

NIETZSCHE, F. Genealogia da Moral. Tradução de Paulo César de Souza. São Paulo: Companhia das Letras, 1999.

POTTS, C. The expressives dimension. Theoretical Linguistics, Kosice, v. 33, n 2, 2007. p. 165-198. Disponível em: <http://www.degruyter.com/view/j/thli.2007.33.issue-2/tl.2007.011/tl.2007.011.xml>. Acesso em: 12 nov. 2016.

RICHARD, M. When truth gives out. Oxford: Oxford University Press, 2008.

SAYRE-McCORD, G. Moral Realism. In: ZALTA, E. N. (Ed.) Stanford Encyclopedia of Philosophy. Standford: Standford University, 2015. Disponível em: <http://plato.stanford.edu/entries/moral-realism/>. Acesso em: 11 dez. 16.

\section{POLÊM!CA $\mid$ LABORE}


SENNET, A.; COPP, D. What kind of a mistake is it to use a slur? Philosophical Studies, New York, v. 172, n. 4, 2014. p. 1079-1104. Disponível em: <http://link.springer.com/article/10.1007/s11098-014-03384/fulltext.html>. Acesso em: 12 nov. 2014.

Recebido em: 06/04/2017.

Aceito em: 30/12/2017.

\section{POLÊM!CA $\mid$ LABORE}

Polêmica - Revista Eletrônica da Uerj - Rua São Francisco Xavier, 524, $1^{\circ}$ andar bloco D, sl.1001 • Tels.: +55 21 2334-4088/4087 • http://www.e-publicacoes.uerj.br/index.php/polemica/index http://www.labore.uerj.br • laboreuerj@yahoo.com.br 